\title{
Short-term effect of oil-mulch on vegetation dynamic; Integration of ecological and remote sensing-based approaches
}

\author{
Noredin Rostami ${ }^{1}$, Haji Karimi ${ }^{1}$, Mohsen Tavakoli ${ }^{1}$, and Reza Omidipour ${ }^{1}$ \\ ${ }^{1}$ Ilam University
}

January 25, 2021

\begin{abstract}
Wind erosion is one of the desertification results and is among the natural processes that mostly occur under dry conditions and high wind velocity. Using oil-mulches is one of the common methods to stabilize sand dunes. The current study aimed to investigate the short-term effects of oil-mulch on vegetation attributes (i.e., cover and diversity) and rangeland condition score (RCS) using integrated ecological and remote sensing-based approaches in arid regions of Southwestern Iran. A vegetation survey was carried out in 2019 in the oil-mulched and control area, and a remotely sensed vegetation index (MSAVI) was calculated for 2017 and 2019. The results indicate that one year after treatment, compared to the control area, vegetation cover $(30 \pm 17.11$ vs. $17 \pm 5.44 \%)$ and litter ( $4.6 \pm 2.18$ vs. $0.94 \pm 1.55 \%)$ increased significantly in the oil-mulched area, while bare soil $(65.20 \pm 17.34$ vs. $82.31 \pm 5.84 \%)$ decreased. Further, diversity indices (Species evenness, Shannon, and Simpson indices) declined by applying oil-mulch $(88 \%, 63 \%$, and $71 \%$, respectively). The rangeland condition score was significantly higher in the oil-mulched area than in the control area $(22 \pm 1.86$ vs. $12 \pm 0.88 ; \mathrm{P}<0.001)$. Comparing MSAVI between 2017 and 2019 showed that vegetation cover increased $44.8 \%$. Based on the results, it can be suggested that planting native palatable species in an oil-mulched area with the exclusion of livestock grazing is likely to increase the benefits of oil-mulch treatment and will lead to better rangeland condition score.
\end{abstract}

\section{Introduction}

Wind erosion, the movement of course and fine particles by wind, is among natural process that mostly occurs under dry conditions and high wind velocity (Mirhasani et al., 2019; Jarrah et al., 2020), and degrade more than one-third of the 'Earth's land surface (Fattahi et al., 2020). The wind erosion may be accelerated by anthropogenic pressures such as overgrazing rangelands, excessive clearances of native vegetation, deforestation, abandoning farmland, monoculture systems, over-harvesting vegetation, or leaving cultivated lands fallow for a long time (He et al., 2006; Chen et al., 2013), resulting in an increase in the rates of soil loss. Wind erosion decreases water quality and negatively impacts biodiversity and climate changes (Lal, 1994; Fattahi et al., 2020). In addition, the negative effects of wind erosion on soil nutrients have been reported; wind erosion may negatively affect nutrients such as nitrogen by blowing off the most fertile topsoil (Lei et al., 2019). Wind erosion may also damage young plant tissues (Zheng et al., 2020) and accelerate shrub expansion, resulting in alteration of plant community composition (Alvarez et al., 2012). Therefore, wind erosion is categorized as one of the most critical global environmental issues in recent decades.

Mulching is a common method among several methods and materials that have been evaluated to find suitable stabilizers for controlling wind erosion (Tibke, 1988; Manorama et al., 2021). Mulches are natural or artificial materials and are used to protect the soil from the damage of various factors such as wind and rain (Refahi, 2009). Oil (petroleum) mulch (hereafter oil-mulch) is one of the high-cost chemical mulches which can be sprayed over sand dunes to assist with re-vegetation (Amiraslani and Dragovich, 2011) and referes to oil products which are made of hydrocarbon mixtures and are used to cement sand particles (more details in Shojaei et al., 2020). Application or spraying of oil-mulches on the degraded and exposed soil to erosion 
reduces water evaporation (Chen et al., 2007), resulting in soil moisture manitenance and preventing sudden temperature changes (Ramakrishna et al., 2006). Also, oil-mulches facilitate plant establishment and growth conditions and, therefore, increase fertilization and soil productivity (Shojaei et al., 2020). For example, Jafarian (2006) reported that in the oil-mulched area in the central part of Iran in Kermen province, the germination ofHaloxylon persicum was nearly three times greater than that found in untreated surfaces. Also, further effects of oil-mulch treatments in stabilizing sand and encouraging seed germination have been reported (Farahpour et al., 2005). In this regard, the positive effects of oil-mulches application have been reported in terms of soil organic matter, soil water holding capacity, and soil organisms' amount and activity (Pouyafar and Asgari Moghadam, 2006). However, the relative contributions of the oil-mulch treatment to vegetation diversity and condition have not received a great deal of attention, especially in arid regions.

Although the oil-mulche effects reduce by time, their application's main goals are to increase soil stability and provide an opportunity for the establishment of other biological activities such as planting and seeding (Refahi, 2009). Generally, the Iranian Ministry of oil provides the oil-mulches at no cost for the purpose of sand stabilization. The first attempt to stabilizing shifting sand dunes and combating desertification was conducted using oil-mulch on 40 ha of dunes at Hamidieh, Albaravayeh, and Albaji in Khuzestan Province in September 1959 (Amiraslani and Dragovich, 2011). Following this project's successful results, nearly 190,000 hectares of sand dunes were stabilized using oil-mulch over the 30 years, and this combat with desertification continues.

Satellite imagery and remote sensing (RS) techniques are among the popular methods to investigate vegetation cover and dynamic across extent areas such as mulched areas (i.e., Hashemimanesh and Matinfar, 2012). however, few studies have been done using RS to evaluate the effectiveness of oil-mulches treatment, especially in Iran's arid regions. Ilam province in western Iran approximately contains 2000 ha dunes area; known as the Abougovair region; 40\% of this region speared using oil-mulch in 2018. While, to continue this process, there is no information about the results of oil-mulch treatment on vegetation diversity and condition yet. Therefore, the current study tried to answer these following equations:

(1): Does short-term (one-year) oil-mulch treatment increase plant diversity (richness, evenness, and diversity) and vegetation components (percent of vegetation cover, litter, and bare soil)?

(2): Does short-term (one-year) oil-mulch treatment significantly increase vegetation conditions and RCS?

(3): Do RS tools (i.e., vegetation indices) have the potential for revealing vegetation change pre- and postoil-mulch treatments?

\section{Materials and Methods}

\section{Study area}

The study was carried out in 2658 ha of desertic arid area in the Abougovair region (extended form $32^{\circ} 13^{\prime}$ $17^{\prime \prime}$ to $32^{\circ} 16^{\prime} 56^{\prime \prime} \mathrm{N}$ and $47^{\circ} 43^{\prime} 16^{\prime \prime}$ to $47^{\circ} 48^{\prime} 30^{\prime \prime} \mathrm{E}$ ), located in Dasht-Abbas town, in southern part of Ilam province, Iran (Fig. 1). In this region, sand dune (1018.6 ha), poor rangeland (1307 ha), non-rain fed (182.9 ha), and rain-fed (149.6 ha) are the main land uses, and agriculture and animal husbandry are the main occupations of the people. The mean annual precipitation, potential evapotranspiration, and temperature were $210 \mathrm{~mm}, 3857.5 \mathrm{~mm}$, and $26.2{ }^{\circ} \mathrm{C}$, respectively. The altitude in the studied area varied between 60 to $220 \mathrm{~m}$ above sea level, and the slope is less than $8 \%$. The soil type in the study area is Inceptisols, based on USA classification.

The desertification in this arid region is mainly due to climatic conditions, improper extraction of groundwater, population growth, degradation of pastures and rangeland, increase in the number of livestock, and expansion of agricultural lands. To combat desertification, with the approval of the Forests, Range and Watershed Management Organization of Iran, it was decided to stabilize an area (about 400 ha) of this region using excess petroleum materials (i.e., oil-mulch). Therefore, in 2018, 8.2 ton/ha oil-mulch was sprayed to stabilize sand dunes and facilitate plant establishment. 


\section{Field vegetation sampling}

The vegetation cover field data were collected using systematic-random design at the maximum growing season, April 2019. In each site, four randomly selected $200 \mathrm{~m}$ transects were placed, then 5 quadrates $(2 \times$ $2 \mathrm{~m}$ ) systematically placed at 50-m intervals along the transect lines, with a total of 20 quadrates in each site. Within each quadrat, vegetation characteristics such as total percentage of canopy cover (\%), bare soil (\%), litter (\%) and stone cover (\%) were recorded. Above-ground vegetation biomass also was determined by plant cutting ( $1 \mathrm{~cm}$ above soil surface). In addition, to calculate the species diversity indices, the cover of each plant species was recorded separately.

Figure 1. The geographical location of the study area in Iran and Ilam province.

\section{Vegetation condition}

Vegetation condition referrs to the practical representation of the major successional stages of broad plant communities (Parker, 1954) and is mostly used to determine and assess the management practices and improvements (Bashari \& Smith, 2010). Although, there are several approaches to determine vegetation condition such as the four-factor method (Parker, 1954), six-factor method (Dnubenmire, 1959), climax method (Parker, 1954), frequency method (Fox, 1984), and the Australian method (DPIF, 2004), the fourfactor method is used frequently/repeatedly in Iran, to determine vegetation condition, compared to other mentioned methods. However, to overcome the problems of the four-factor method in arid and semi-arid regions, it was modified to the six-factor (Mesdaghi, 1998). In the current study, we use a modified six-factor method that is developed for arid and semi-arid regions of Western Iran by Faramarzi et al. (2010). This method is based on four factors including litter frequency (LF), percentage of weighted palatability classes (WPC), percentage of potential biomass production (ratio of actual biomass to potential biomass), and percentage of bare soil (as a measure of soil conservation) (Table 1).

Table 1. The score of different factors for range condition and classes of range condition scores (adapted from Faramarzi et al., 2010). BS: bare soil, LF: litter frequency, WPC: weighted palatability classes, BP: biomass production, RCS: rangeland condition score.

\section{Species diversity measurement}

To ecologically assess the mulching effects, species diversity indices were used, including species richness, species evenness, Shannon, and Simpson diversity indices based (Table 2).

Table 2. The species diversity indices used

$\mathrm{S}$ : number of species; H: Shannon diversity index; $\mathrm{p}_{\mathrm{i}}$ : relative frequency; D: dominance

\section{Remote sensing approach}

Remotely sensed vegetation indices are among the main tools used in vegetation surveys (Mirzaei et al., 2015; Abdolalizadeh et al., 2020; Zarei et al., 2020). In arid and semi-arid regions, the soil brightness may accelerate the surface reflectance and causes exaggeration in vegetation cover condition; therefore, some Vegetation Indices (VIs) are developed to be used in such regions by considering the soil line parameters (slope and intercept) that are produced by regression between red and near-infrared bands in bare soil patches. In the current study, we used the Modified Soil-Adjusted Vegetation Index (MSAVI) suggested by Qi et al. (1994). The MSAVI is based on a modification of the L factor (soil adjustment factor) of the SAVI index (Soil-Adjusted Vegetation Index) that tended to make a better correction of the soil background brightness in different vegetation cover conditions. Previously, in the SAVI index, the L factor defined according to the density of the vegetation and the climatic conditions of an area (Qi et al., 1994), which replaced by its calculation based on the slope of the background soil line and other vegetation indices (NDVI and WDVI). The MSAVI vegetation index expressed as the following formula (Qi et al., 1994):

$$
\frac{N I R-R e d}{(N I R+R e d+L)} \times(1+L) ; \quad L=1-2 \gamma(N D V I \times W D V I)
$$


Where;

$\mathrm{NIR}=$ reflectance in the near-infrared band (expressed as reflectance)

$\mathrm{RED}=$ reflectance in the visible red band (expressed as reflectance)

NDVI $=$ Normalized Difference Vegetation Index $(($ NIR-RED $) /($ NIR+RED $))$

WDVI $=$ Weighted Difference Vegetation Index (NIR- $\gamma$ RED)

$\gamma=$ Slope of the background soil line

In this formula, the soil adjust factor is selected as an empirical equation to decrease with decreasing vegetation cover, as in the case in semi-arid regions (Qi et al., 1994). In addition, the L factor ranges from 0 to 1 and multiplied by two (2L) to increase the L dynamic range (Eastman, 2016).

The differencing method was used to detect spatio-temporal trend changes (increasing, decreasing and no changes) between pre- and post-mulch treatment (Singh, 1989). In this method, the digital value of the second map (i.e., MSAVI map of 2017) is subtracted from the first map (i.e., MSAVI map of 2019), pixel by pixel (Mirzaei et al., 2015). This method's results include positive, negative and zero pixels, indicating increasing, decreasing, and no changes in vegetation cover, respectively. However, this method needs to determine the change threshold, to distinguish the changing area (increasing and decreasing) from the nochange area (Fung and Ledrew, 1988). In the current study, we employed a statistical method (Mirzaei et al., 2015) based on the following equation:

$$
Z=\frac{X_{i}-X}{S}
$$

Where $\mathrm{Xi}$ is the numerical value of each pixel, $X$ is the mean score of the pixels, and $\mathrm{S}$ is standard deviations.

Finally, to statistically compare the control and mulch treated area, we design a network of random points including 100 points in both the control and the mulch treated area (Fig. 1). The MSAVI values are extracted and analyzed (see statistical analysis section).

\section{Statistical Analysis}

The normal distribution and homoscedasticity were assessed using the Shapiro-Wilk Test and Levene's Test, respectively. To compare the vegetation characteristics (Total cover, bare soil, litter and stone cover), vegetation condition scores (BS, LF, WPC, Prod and RCS) and species diversity indices (species richness, species evenness, Shannon and Simpson diversity indices), independent Student's t-Test was used. To assess the significant difference between pre and post mulching and between the control and the mulch treatments, we used a two-way ANOVA. In this model, year (pre vs. post mulching; 2017 and 2019), treatment (control vs. mulch) and their interaction were introduced as independent variables, and vegetation cover extracted by MSAVI was introduced as the dependent variable to the model. In addition, a t-student test was conducted to detect significant differences between pre and post mulching and between control and mulch treatments. All statistical tests were performed using the SPSS var. 21.0 software.

\section{Results}

The results showed that gathered data satisfy assumptions of normal distribution (all $P>0.05$ ) and homogeneity of variance (all $P>0.05$ ) (Table 3). Based on the results, vegetation components significantly varied between control and mulch treated sites (all $P<0.05$ ), in which total cover and litter increased both about $76 \%$ while bare soil decreased about $26 \%$ under mulch treated (Fig. 2). Species richness was not varied between control and mulch treated sites $(t$-value $=-0.067$ and $P=0.947)$. In contrast, species evenness, Shannon, and Simpson diversity indices were negatively affected by mulch treatment (Table 3 and Fig. 2). For example, applying mulch treatment resulted in a decline in species evenness, Shannon, and Simpson diversity indices about $88 \%, 63 \%$, and $71 \%$, respectively (Fig. 2). 
Table 3. Results of normal distribution (Shapiro-Wilk Test), homoscedasticity (Levene's Test), and independent t-test between vegetation and diversity component in control and mulch treated sites. significant values are shown by bold numbers. The non-significant values in Shapiro-Wilk and Levene's tests indicate normal distribution and homogeneity in variance, respectively.

Figure 2. Mean \pm SE comparison of vegetation and diversity components in control and mulch treated sites. significant differences are indicated by different letters.

All RCS parameters (BS, LF and BP) and total RCS significantly differed between control and mulch treated sites (all $P<0.001)$ while WPC was not significantly different between control and mulch treated sites $(t$ -value $=1.226$ and $P=0.236$ ) (Table 4 ). In addition, RCS class in control and mulch treated areas were very poor and poor, respectively.

Table 4. The comparison results of RCS and their components. BS: bare soil, LF: litter frequency, WPC: weighted palatability classes, BP: biomass production, RCS: rangeland condition score. Significant values are shown by bold numbers.

Before calculating MSAVI maps of 2017 and 2019, the slope and intercept of soil lines regression were calculated by fitting a linear regression between the red and infrared bands (Table 5).

Table 5. The soil line parameters (slope and intercept) are based on a linear regression between the red (as the dependent variable) and infrared bands (as an independent variable) and good of fitness indices.

Then, the MSAVI maps of 2017 and 2019 were produced and reclassified (Fig. 3). As shown in Fig. 4, the vegetation cover significantly increased in 2019 compared to those found in 2017.

Figure 3. The vegetation cover maps based on remotely sensed MSAVI index

The results of map differencing showed that vegetation cover of extent area of studied regions was not varied $(52.4 \%)$ or increased $(44.8 \%)$ between 2017 and 2019; however, vegetation cover in some small areas (northwest) was decreased (2.8\%) (Fig. 4).

Figure 4. Vegetation cover change monitoring using the differencing method

The results of map differencing showed that vegetation cover of extent area of our studied regions was not varied $(52.4 \%)$ or increased $(44.8 \%)$ between 2017 and 2019; however, vegetation cover in some small areas (northwest) was decreased (2.8\%) (Fig. 4).

Finally, two-way ANOVA results showed that years (2017 vs. 2019), treats (control vs. mulch), and their interaction had significant effects on vegetation cover value extracted by the MSAVI index (Fig. 5). Based on the results, vegetation cover was greater in 2019 than that of 2017 and also greater in the mulched site in 2019 than the controls site, while there was no difference between vegetation cover in controls and mulch sites in 2017 (Fig. 5).

Figure 5. Results of two-way ANOVA of vegetation cover extracted by MSAVI index for pre and post applying mulching. The significant differences are shown by different letters. ${ }^{* * *}$, indicate significant effects at $\mathrm{P}<$ 0.001 .

\section{Discussion}

Spraying oil-mulch significantly increases vegetation cover and litter percents while it simultaneously decreases the percent of bare soil (Table 3 and Fig. 2). These positive effects of oil-mulch treatment have probably resulted from three mechanisms include 1) stabilizing effects on sand dunes (Wuddivira et al., 2013), 2) decreasing water evaporation and preserving available soil moisture (Kowsar et al., 1969; Mulumba and Lal, 2008; Liu et al., 2020) and 3) increasing the rate of seedling survival (Akbarian and Mosavi, 2006) and germination (Farahpour et al., 2005; Jafarian, 2006). Arid and semi-arid regions are known as water-limited areas (Shojaei et al., 2020), and thereby, soil moisture is an important factor that controls the seedling germination, survival, and growth (Zhenghu et al., 2004). It has been reported that oil-mulch treatment could 
provide more benefits in encouraging seed germination than other tested sand stabilizers (Farahpour et al., 2005), mainly due to the presence of more soil moisture and temperature. In addition, the positive effects associated with the use of oil-mulch were reported in terms of soil organic matter, soil water holding capacity, and the amount and activity of soil organisms (Pouyafar and Asgari Moghadam, 2006; Hashemimanesh and Matinfar, 2012).

Although it is not expected that after short-term oil-mulch treatment, an increase occurrs in amount of plant litter, our finding may even indicate negative effects (i.e., drying effects on the plants) of oil-mulch treatment on the initial vegetation. On the other hand, however, the increase in litter accumulation may increase along time after oil-mulch treatment, resulting in an increase in soil fertility, infiltration, and stability as well as a decline in soil erosion (Shojaei et al., 2020). The positive effects of plant litter in increasing soil water holding capacity, water retention, and moisture loss reduction from evaporation were also reported (El-Kader et al., 2010; Simmons et al., 2010; Rodrigo-Comino et al., 2020). Similarly, a positive linear effect of mulch application rate on soil organic matter concentration was reported by Duiker and Lal (1999). In addition, an increase in litter accumulation may increase the hydraulic conductivity of soil stability (Moazzemi et al., 2013) and improve the specific mass and soil porosity (Shojaei et al., 2020), increasing the strength of the soil surface and reduction of the soil erosion (Singh and Agrawal, 2008; Mulumba and Lal, 2008).

Our results indicate that the short-term application of oil-mulch significantly decreases bare soil percent (Table 3 and Fig. 2). In line with this result, Hashemimanesh and Matinfar (2012) reported that the petroleum mulch project in southwestern Iran decreased sand dune areas from $66.4 \%$ in 1991 to $56 \%$ in 2002. Similarly, Azoogh et al. (2018) results indicated that petroleum mulching-biological fixation practices promoted the restoration of vegetation cover in the sand dunes. Therefore, this result is likely explained by the positive effects of oil-mulch treatment on vegetation cover and litter.

Also, results indicate that species diversity and evenness are negatively, and species richness is neutrally related to oil-mulch treatment. Generally, in a short-term oil-mulch application, negative (Karami khaniki, 2009; Adeli, 2012; Gholami Tabasi et al., 2015) and neutral (Jafari et al., 2017) effects on vegetation diversity are reported. In addition, Gholami Tabasi et al. (2014) found that applying the plantation and oil-mulching negatively and neutrally affects vegetation attributes (i.e., cover and density) of Astragalus squarrosus and Convolvolus hamadae, respectively. In contrast, Tabasi (2014) indicated that oil-mulch did not negatively affect plants; however, it may increase vigor and biomass in the plant's stands. Therefore, it seems that these negative effects of oil-mulch treatment are likely related to the drying effects of oil-mulch on the plants, especially in the early period after the application of oil-mulches. While, by the passage of time since mulching, plant diversity could increase in the mulch-treated area even more than the control area. For example, Khalilimoghadam and Bodaghabadi (2020) reported that 'Shannon's diversity index increased over the time period of 30-40 years compared to the initial years of sand dunes stabilization ( $<5$ years).

The current study was designed to fill the gap in our knowledge about oil-mulching effects on RCS. The results showed that RCS increased one year after the oil-mulch treatment, i.e., it changes from very poor class (RCS $=12)$ to poor class $(\mathrm{RCS}=22)$ in control and oil-mulch treated. In this study, RCS was determined based on four parameters, including BS: bare soil, LF: litter frequency, WPC: weighted palatability classes, BP: biomass production (Table 1). As shown previously, results demonstrate that short term oil-mulching increase vegetation cover and litter and decrease bare soil percent. In addition, a strong positive association between vegetation cover and biomass production was reported (Flombaum and Sala, 2007; Pordel et al., 2018; Louhaichi et al., 2018). Therefore, it can be said that oil-mulch treatment leads to better RCS by affecting vegetation attributes (i.e., cover, biomass). On the other hand, however, among all RCS parameters, only WPC was not significantly different between control and mulch treated sites. This difference mainly related to non- or low-palatable plants that reintroduced and planted with mulching such as Citrullus colocynthis L., Prosopis juliflora (Sw.) DC.,Eucalyptus camaldulensis and Ziziphus spina-christi (L.) Desf. Considering that native species had a greater chance to survive, establish and grow in such arid condition (Jafari et al., 2018; Bazgir et al., 2020), the management practices after oil-mulch treatment (i.e., selection of suitable plants) had a vital role in achieving successful results. 
To compare the vegetation cover pre and post oil-mulch treatment (one year before (2017) and one year after (2019), we used the remotely sensed vegetation index extracted based on Landsat 8 OLI imagery (i.e., MSAVI). Results demonstrated that vegetation cover greatly increased in 2019 compared to those found in 2017, indicating positive effects of oil-mulching and confirmed our previous results. This increase in vegetation cover compared to the control area mainly resulted from two reasons, including 1) positive effects of oil-mulch treatment and 2) increased amount of precipitation in 2019 compared to 2017 (210.7 and 638.8 $\mathrm{mm}$, respectively). As previously noted, soil moisture and instability are the main limitations in an arid area, and any factor like oil-mulch treatment which increases the soil moisture will lead to an increase in vegetation cover (Akbarian and Mosavi, 2006; Mulumba and Lal, 2008; Wuddivira et al., 2013; Shojaei et al., 2020). This conclusion could be confirmed by the two-way ANOVA results that revealed that vegetation cover was greater for 2019 than 2017 and in the oil-mulch treated site in 2019 compared to the correspondence control site (Fig. 5). In addition, no significant difference was observed between controls and mulch sites in 2017, highlighting the importance of oil-mulch treatment. Therefore, the greater vegetation cover in 2019 synergically responded to the joint effects of oil-mulching and an increase in precipitation.

\section{Conclusion}

The increase in soil moisture and stabilizing sand dunes is the primary need/requisite to establish vegetation in arid regions, and short- and long-term monitoring of management practices could provide better insight into choosing the method. In the current study, an integration of ecological and remotely sensed approaches was used to monitor the short-term vegetation attributes and diversity and RCS.

Our results highlight the positive short-term effects of oil-mulch treatment on vegetation cover and RCS, while it is challenged by the negative effects of oil-mulch treatment on diversity. In addition, using the native palatable species to planting in an oil-mulched area with the exclusion of livestock grazing is likely to increase the benefits of oil-mulch treatment resulted in better RCS. Finally, we indicate the high potential of remotely sensed vegetation index in order to extend the monitoring of rehabilitation schemes.

\section{Acknowledgement}

This article is taken from a research project entitled Evaluation of the efficiency of oil-mulch in wind erosion and stabilization of sand dunes in Abu-Ghoveir area of Dehloran, Iran. We would like to thank the Department of Natural Resources of Ilam Province for its cooperation and funding.

\section{Conflict of Interest}

The authors have no conflict of interest to declare.

\section{References}

Abdolalizadeh, Z., Ghorbani, A., Mostafazadeh, R. \& Moameri, M. (2020). Rangeland canopy cover estimation using Landsat OLI data and vegetation indices in Sabalan rangelands, Iran. Arabian Journal of Geosciences, 13(6),1-13.

Adeli, M. (2012). Study on the effect of petroleum mulch on soil properties, vegetation and erosion in the Sarakhs plain. Thesis of Desert and Dry lands Management. Gorgan University of Agricultural Science and Natural Resources. 82 p.

Akbarian, M., Mosavi, M. (2006). Investigating two mulch techniques with planting before and after spraying mulch: tools for dune fixation in BiahiChendi area, Hormozgan Privince, Iran. International Symposium on Drylands Ecology and Human Security, Dubai, Abstract 2006/192.

Alvarez, L.J., Epstein, H.E., Li, J. \& Okin, G.S. (2012). Aeolian process effects on vegetation communities in an arid grassland ecosystem. Ecology and Evolution, 2 (4), 809-821.

Amiraslani, F. \& Dragovich, D. (2011). Combating desertification in Iran over the last 50 years: An overview of changing approaches. Journal of Environmental Management, 92 (1), 1-13. 
Azoogh, L. and Jafari, S., 2018. Interaction of petroleum mulching, vegetation restoration and dust fallout on the conditions of sand dunes in southwest of Iran. Aeolian research, 32, 124-132.

Bashari, H. \& Smith, C.S. (2010). Accommodating uncertainty in grazing land condition assessment using Bayesian Belief Networks. Bayesian 'Network'.(Ed. Ahmed Rebai.) pp , 341-354.

Bazgir, M., Omidipour, R., Heydari, M., Zainali, N., Hamidi, M. \& Dey, D.C. (2020). Prioritizing woody species for the rehabilitation of arid lands in western Iran based on soil properties and carbon sequestration. Journal of Arid Land, 1-13.

Chen, L., Gao, J., Ji, Y., Bai, Z., Shi, M. \& Liu, H. (2013). Effects of particulate matter of various sizes derived from suburban farmland, woodland and grassland on air quality of the central district in Tianjin, China. Aerosol and Air Quality Research , 14 (3), 829-839.

Chen, S.Y., Zhang, X.Y., Pei, D., Sun, H.Y. \& Chen, S.L. (2007). Effects of straw mulching on soil temperature, evaporation and yield of winter wheat: field experiments on the North China Plain. Annals of Applied Biology , 150 (3), 261-268.

Dnubenmire, R. (1959). A canopy-coverage method of vegetation analysis.Northwest Sci , 33 , 43364.

DPIF: Department of Primary Industries and Fisheries. (2004). Stock take, balancing supply and demands, DPI \& F, Brisbane, Australia, 77p.

Duiker, S.W. \& Lal, R. (1999). Crop residue and tillage effects on carbon sequestration in a Luvisol in central Ohio. Soil and Tillage Research ,52 (1-2), 73-81.

Eastman, J. R. (2016). TerrSet Geospatial Monitoring and Modeling System. Manual version 18.30. Clark University, Worcester.

El-Kader, A., Shaaban, S.M. \& El-Fattah, M. (2010). Effect of irrigation levels and organic compost on okra plants (Abelmoschus esculentus L.) grown in sandy calcareous soil. Agric Biol JN Am ,1 (3), 225-231.

Farahpour, M., Ghayour, F.A., Sherbaf, H., \& Yousefizadeh, A. (2005). Comparison of water absorbent and non-oil mulch with oil mulch on seed germination and sand dune stabilization. Iranian Journal of Range and Desert Research 12, 121-134.

Faramarzi, M., Kesting, S., Isselstein, J. \& Wrage, N. (2010). Rangeland condition in relation to environmental variables, grazing intensity and livestock 'owners' perceptions in semi-arid rangeland in western Iran. The Rangeland Journal , 32 (4), 367-377.

Fattahi, S.M., Soroush, A. \& Huang, N. (2020). Wind erosion control using inoculation of aeolian sand with cyanobacteria. Land Degradation \& Development, 31(15), 2104-2116. doi:10.1002/ldr.3590

Flombaum, P. \& Sala, O.E. (2007). A non-destructive and rapid method to estimate biomass and aboveground net primary production in arid environments. Journal of Arid Environments , 69 (2), 352-358.

Fox, H.D. (1984). A plant frequency method for determining range condition (inventory, evaluation). $\mathrm{PhD}$ thesis. The University of Arizona. 89 p.

Gholami Tabasi, J., Jafary, M., Azarnivand, H \& Sarparast, M. (2015). Studying the Effect of Petroleum Mulch on the Vegetation andSoil Attributes of Sandy Deserts (Samad Abad of Sarakhs). Desert Management, $2(4), 43-50$.

Gholami Tabasi, J., Jafary, M., Azarnivand, H. \& Sarparast, M. (2014). Vegetation and Soil Properties of a Sandy Desert Affected by Shrub (Haloxylon aphyllum) Plantation and Oil Mulching. Enviromental Resources Research, 2(1), 67-76.

Hashemimanesh, M. and Matinfar, H., 2012. Evaluation of desert management and rehabilitation by petroleum mulch base on temporal spectral analysis and field study (case study: Ahvaz, Iran). Ecological Engineering, 46, 68-74. 
He, X., Zhou, J., Zhang, X. and Tang, K. (2006). Soil erosion response to climatic change and human activity during the Quaternary on the Loess Plateau, China. Regional Environmental Change , 6 (1-2), 62-70.

Jafari, M, Tavili, A, Panahi, F, Zandi EE \& Ghorbani, M. (2018). Reclamation of Arid Lands. Springer, $267 \mathrm{p}$.

Jafarian, V. (2006). The effect of petroleum mulching on seed germination of desert plants in Iran. International Symposium on Drylands Ecology and Human Security, Dubai, Abstract 2006/154.

Jarrah, M., Mayel, S., Tatarko, J., Funk, R. \& Kuka, K. (2020). A review of wind erosion models: Data requirements, processes, and validity. Catena , 187, 104388.

Karami khaniki, A. (2009). Regulations, Standards and technical criteria's of using oil mulch. Tehran's Poone press, Iran, $164 \mathrm{p}$.

Khalilimoghadam, B. \& Bodaghabadi, M.B. (2020). Factors influencing the relative recovery rate of dunes fixed under different sand-fixing measures in southwest Iran. Catena , 194 , 104706.

Kowsar, A., Boersma, L. and Jarman, G.D., 1969. Effects of petroleum mulch on soil water content and soil temperature. Soil Science Society of America Journal, 33(5), pp.783-786.

Lal, R. (1994). Soil erosion by wind and water: problems and prospects.Soil erosion research methods , 2 , $1-9$.

Lei, L., Zhang, K., Zhang, X., Wang, Y.P., Xia, J., Piao, S., Hui, D., Zhong, M., Ru, J., Zhou, Z. \& Song, H. (2019). Plant feedback aggravates soil organic carbon loss associated with wind erosion in Northwest China. Journal of Geophysical Research: Biogeosciences ,124 (4), 825-839.

Liu, T., Cao, Y., Zhang, Y., Wang, R., Xiao, H., Wang, B. and Si, L., 2020. Soil environment and growth adaptation strategies of Amorpha fruticosa as affected by mulching in a moderately saline wasteland. Land Degradation \& Development, 31(17), 2672-2683.

Louhaichi, M., Hassan, S., Clifton, K. \& Johnson, D.E. (2018). A reliable and non-destructive method for estimating forage shrub cover and biomass in arid environments using digital vegetation charting technique. Agroforestry Systems, 92 (5), 1341-1352.

Manorama, K., Behera, S.K., Suresh, K., Prasad, M.V., Mathur, R.K. and Harinarayana, P. (2021), Mulching and technological interventions avoid land degradation in intensive oil palm (Elaeis guineensis Jacq) production system. Land Degradation \& Development. doi:10.1002/ldr.3886

Mesdaghi, M. (1998). Range management in Iran. 4th edition, Astane Ghodse Razavi press, Mashhad.

Mirhasani, M., Rostami, N., Bazgir, \& Tavakoli M. (2019). Threshold friction velocity and soil loss across different land uses in arid regions: Iran. Arab J Geosci, 12, 91. doi:10.1007/s12517-019-4252-0.

Mirzaei, J., Mohamadi, A., Heidarizadi, Z., Noorolahi, H., \& Omidipour, R. (2015). Assessment of Land Cover Changes Using RS and GIS (Case Study: Zagros Forests, Iran). J. Matr. Environ. Sci , 6 , 2565-2572.

Moazzemi, N., Beige, N., \& Ranjpishe, M. (2013). Comparison of mulch types on the stabilization of shifting sand. National Seminar on Wind Erosion and Dust Storms of Natural Resources and Agriculture Faculty, Yazd University.

Mulumba, L.N. \& Lal, R. (2008). Mulching effects on selected soil physical properties. Soil and Tillage Research, 98 (1), 106-111.

Parker, K.W. (1954). Application of ecology in the determination of range condition and trend. Journal of Range Management ,7 (1), 14-23.

Pordel, F., Ebrahimi, A. \& Azizi, Z. (2018). Canopy cover or remotely sensed vegetation index, explanatory variables of above-ground biomass in an arid rangeland, Iran. Journal of Arid Land, 10 (5), 767-780. 
Pouyafar, A.M., \& Asgari Moghadam, Z. (2006). Investigation of the environmental impacts of oil mulch application. Rangeland and forest journal, 70, 36-41.

QI, J., Chehbouni, A., Huete, A. R., Kerrm Y. H., \& Sorooshian, S. (1994). Modified soil adjusted vegetation index (MSAVI). Remote Sensing of Environment, 48, 119-126.

Ramakrishna, A., Tam, H.M., Wani, S.P. \& Long, T.D. (2006). Effect of mulch on soil temperature, moisture, weed infestation and yield of groundnut in northern Vietnam. Field crops research ,95 (2-3), 115-125.

Refahi, H. (2009). Wind erosion and control. Fifth Edition, Tehran: Tehran University Press. 320.

Rodrigo-Comino, J., Gimenez-Morera, A., Panagos, P., Pourghasemi, H.R., Pulido, M. and Cerda, A., 2020. The potential of straw mulch as a nature-based solution for soil erosion in olive plantation treated with glyphosate: A biophysical and socioeconomic assessment. Land Degradation \& Development, 31(15), 1877-1889.

Shojaei, S., Ardakani, M.A.H. \& Sodaiezadeh, H. (2020). Simultaneous optimization of parameters influencing organic mulch test using response surface methodology. Scientific Reports , 10 (1), 1-11.

Simmons, A.M., Kousik, C.S. \& Levi, A. (2010). Combining reflective mulch and host plant resistance for sweetpotato whitefly (Hemiptera: Aleyrodidae) management in watermelon. Crop Protection ,29 (8), 898-902.

Singh, A. (1989). Review article digital change detection techniques using remotely-sensed data. International journal of remote sensing , 10 (6), 989-1003.

Singh, R.P. \& Agrawal, M. (2008). Potential benefits and risks of land application of sewage sludge. Waste management, 28(2), 347-358.

Tabasi, J. (2014). Sandy deserts vegetation and soil changes due to some wind erosion control steps (Samadabad, Sarakhs). Thesis of range management. University of Tehran. 100 p.

Tibke, G. (1988). Basic principles of wind erosion control.Agriculture, Ecosystems \& Environment, 22 , 103-122.

Tung, F., \& LeDrew, E. (1988). The determination of optimal threshold levels for change detection using various accuracy indexes.Photogrammetric Engineering and Remote Sensing , 54 (10), 1449-1454.

Wuddivira, M.N., Stone, R.J. and Ekwue, E.I., 2013. Influence of cohesive and disruptive forces on strength and erodibility of tropical soils. Soil and Tillage Research, 133, 40-48.

Zarei, A., Asadi, E., Ebrahimi, A., Jafari, M., Malekian, A., Nasrabadi, H.M., Chemura, A. \& Maskell, G. (2020). Prediction of future grassland vegetation cover fluctuation under climate change scenarios. Ecological Indicators, 119, 106858.

Zheng, M., Song, J., Ru, J., Zhou, Z., Zhong, M., Jiang, L., Hui, D. \& Wan, S. (2020). Effects of Grazing, Wind Erosion, and Dust Deposition on Plant Community Composition and Structure in a Temperate Steppe.Ecosystems, 1-18.

Zhenghu, D., Honglang, X., Xinrong, L., Zhibao, D. and Gang, W., 2004. Evolution of soil properties on stabilized sands in the Tengger Desert, China. Geomorphology, 59(1-4), pp.237-246.

Table 1. The score of different factors for range condition and classes of range condition scores (adapted from Faramarzi et al., 2010). BS: bare soil, LF: litter frequency, WPC: weighted palatability classes, BP: biomass production, RCS: rangeland condition score.

Rangeland condition factors

\begin{tabular}{lllll}
\hline & BS (\%) & BS (\%) & LF (\%) & WPC (\%) \\
Min-Max & $0-100$ & $0-100$ & $0-100$ & $100-300$
\end{tabular}


Score

$0-20$

$0-20$

$0-10$

$0-20$

Sum score of RCS and rangeland condition

Sum score of RCS and rangeland condition

$56-65$

$56-65$

$56-65$

46-55 46-55 46-55

$34-45 \quad 34-45 \quad 34-45$

22-33 22-33 22-33

$11-21 \quad 11-21 \quad 11-21$

$0-10$

$0-10$

$0-10$

Table 2. The species diversity indices used

\begin{tabular}{lll}
\hline Diversity components & Equation & References \\
\hline Richness & $\mathrm{S}=$ Number of species & Magurran, 2013 \\
Evenness & $\mathrm{e}^{\mathrm{H}} / \mathrm{S}$ & Buzas and Gibson, 1969 \\
Shannon diversity & $\mathrm{H}=\mathrm{p}_{\mathrm{i}} \ln . \mathrm{p}_{\mathrm{i}}$ & Shannon and Weaner, 1963 \\
Simpson diversity & $1-D$ & Simpson, 1949 \\
\hline
\end{tabular}

S: number of species; H: Shannon diversity index; $\mathrm{p}_{\mathrm{i}}$ : relative frequency; D: dominance

Table 3. Results of normal distribution (Shapiro-Wilk Test), homoscedasticity (Levene's Test), and independent t-test between vegetation and diversity component in control and mulch treated sites. significant values are shown by bold numbers. The non-significant values in Shapiro-Wilk and Levene's tests indicate normal distribution and homogeneity in variance, respectively.

\begin{tabular}{llllllll}
\hline Category & Components & Shapiro-Wilk Test & Shapiro-Wilk Test & Levene's Test & Levene's Test & t-Test & t-Test \\
\hline \multirow{3}{*}{ Vegetation } & Total cover (\%) & 0.937 & $P$-valve & F-value & $P$-valve & t-value & $P$-valve \\
& Bare soil (\%) & 0.937 & 0.225 & 3.126 & 0.10 & 2.342 & $\mathbf{0 . 0 3 9}$ \\
& Litter (\%) & 0.910 & 0.256 & 3.126 & 0.10 & -2.919 & $\mathbf{0 . 0 1 3}$ \\
Diversity & Richness & 0.923 & 0.085 & 2.398 & 0.141 & 4.16 & $\mathbf{0 . 0 0 1}$ \\
& Evenness & 0.950 & 0.092 & 0.282 & 0.603 & -0.067 & 0.947 \\
& Shannon & 0.963 & 0.424 & 1.152 & 0.299 & -4.307 & $\mathbf{0 . 0 0 1}$ \\
& Simpson & 0.957 & 0.536 & 0.008 & 0.929 & -4.775 & $\mathbf{0 . 0 0}$ \\
\end{tabular}

Table 4. The comparison results of RCS and their components. BS: bare soil, LF: litter frequency, WPC: weighted palatability classes, BP: biomass production, RCS: rangeland condition score. Significant values are shown by bold numbers.

\begin{tabular}{lllllll}
\hline Parameters & Mulch & Mulch & Control & Control & t-value & P \\
\hline & Value & Score & Value & Score & & \\
BS (\%) & 55.2 & 8.69 & 77.15 & 4.5 & 3.414 & $>\mathbf{0 . 0 0 1}$ \\
LF (\%) & 4.6 & 0.92 & 0.75 & 0.15 & 4.676 & $\mathbf{P . 0 0 1}$ \\
WPC (\%) & 86.17 & 0.67 & 38.31 & 0.00 & 1.226 & 0.236 \\
BP (\%) & 71.0 & 11.70 & 44.3 & 7.30 & 5.359 & $>\mathbf{0 . 0 0 1}$ \\
RCS score & & 22 & & 12 & 5.351 & $>\mathbf{0 . 0 0 1}$ \\
RCS class & Poor & Poor & Very poor & Very poor & & \\
\hline
\end{tabular}

Table 5. The soil line parameters (slope and intercept) are based on a linear regression between the red (as 
the dependent variable) and infrared bands (as an independent variable) and good of fitness indices.

\begin{tabular}{lllll}
\hline Image year & Slope $(\gamma)$ & Intercept & $R^{2}$ & S.E. of estimate \\
\hline 2017 & 0.882236 & -0.037544 & 0.994 & 0.006 \\
2019 & 0.796376 & -0.038196 & 0.962 & 0.012 \\
\hline
\end{tabular}

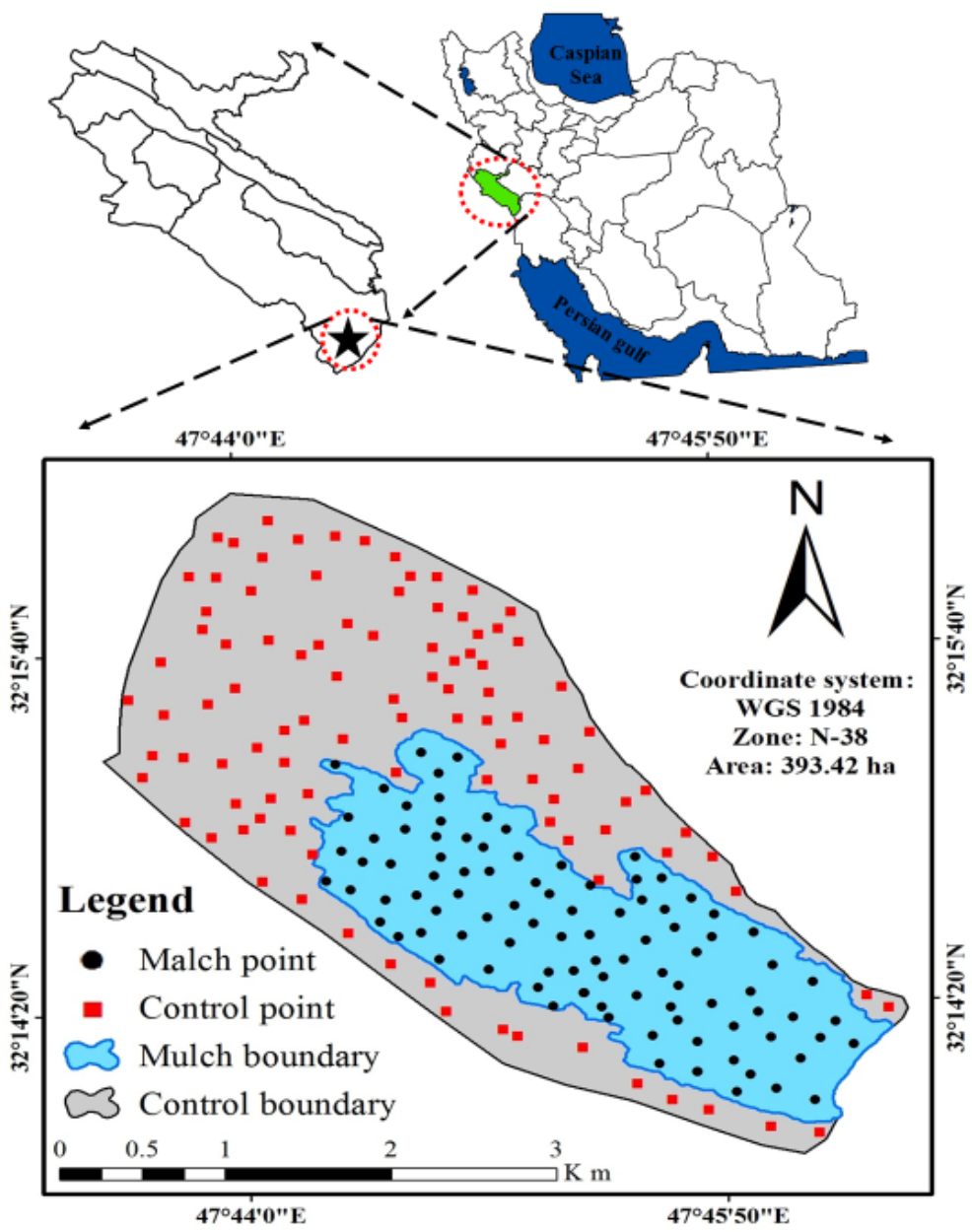



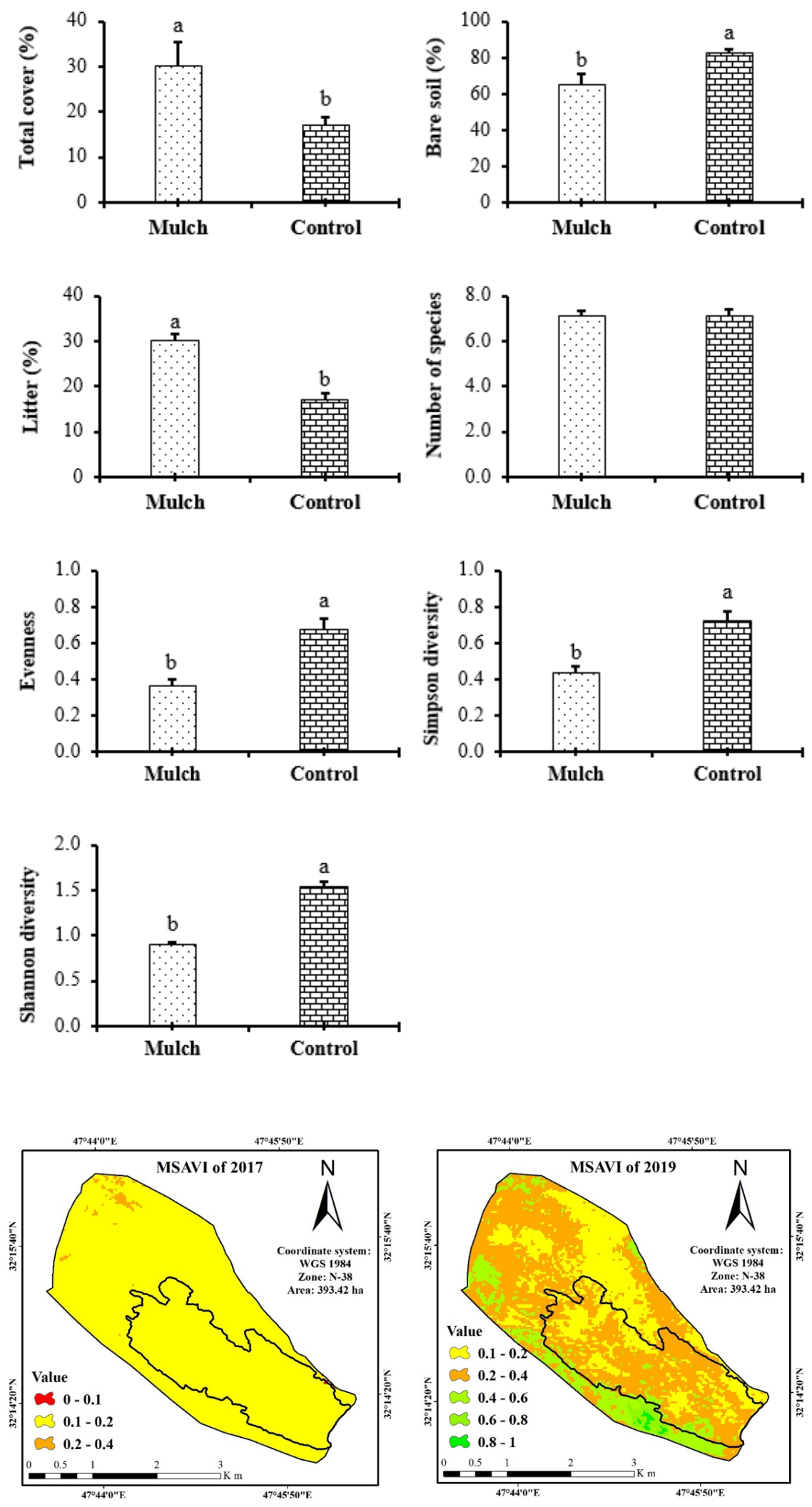

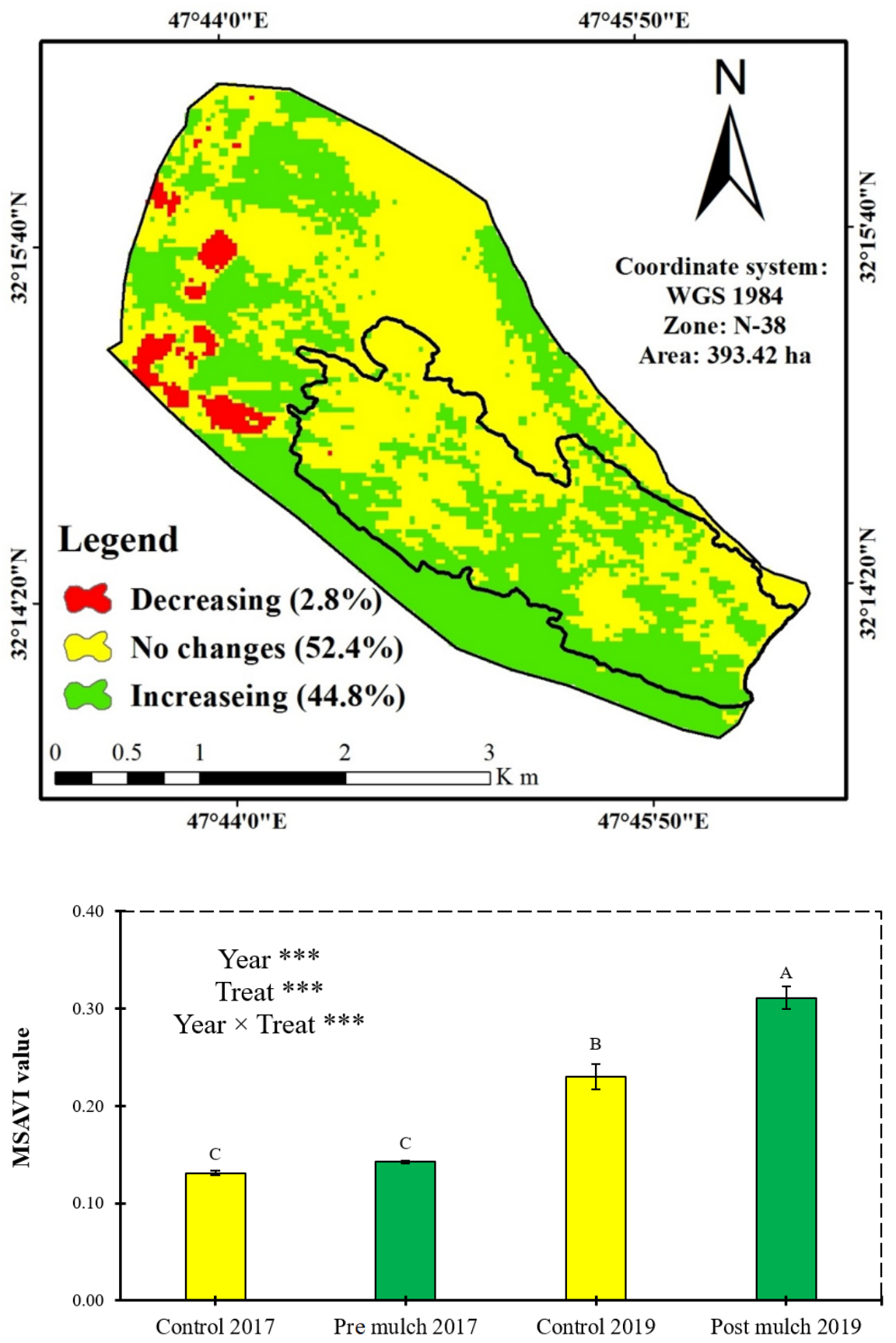